Research Article

\title{
Coupling and Coordination Degree between Urbanization and Ecological Environment in Guizhou, China
}

\author{
Zhengqi Gong $\mathbb{D},{ }^{1}$ Rongjian Mao $\mathbb{D},{ }^{1}$ and JingJun Jiang $\mathbb{D}^{2}$ \\ ${ }^{1}$ School of Economics, Guizhou University of Finance and Economics, Guiyang 550025, China \\ ${ }^{2}$ School of Business, Henan Normal University, XinXiang 453007, China \\ Correspondence should be addressed to JingJun Jiang; jiangjingjun@htu.edu.cn
}

Received 9 August 2021; Revised 24 August 2021; Accepted 25 August 2021; Published 8 September 2021

Academic Editor: Daqing Gong

Copyright ( 2021 Zhengqi Gong et al. This is an open access article distributed under the Creative Commons Attribution License, which permits unrestricted use, distribution, and reproduction in any medium, provided the original work is properly cited.

This paper intends to examine the coupling and coordination degree (CCD) between the urbanization and ecological environment in Guizhou, China. The entropy weight method and coupling effect model were used to calculate the CCD between the urbanization and ecological environment of Guizhou and each of its prefectures. The results show the following: (1) there is an inverted U-shaped relationship between the urbanization and ecological environment deterioration in Guizhou, which can be described by the Kuznets curve; (2) both the urbanization and ecological environment improve with the increase in the CCD; (3) unlike the traditional urbanization path, the urbanization in Guizhou features the parallel progress of industrialization and ecological environment protection. These results prove another possibility of the Kuznets curve: the curve can reach the turning point without high urbanization. This new urbanization path of balance-upgrading provides an important reference for backward areas to realize low-carbon economy and sustainable development at the same time.

\section{Introduction}

Guizhou, a province in southwestern China, is an important ecological barrier in the upper reaches of the Yangtze River and the Pearl River. The province faces both structural ecological environment problems that are common in China and special problems like soil erosion and serious lagging of infrastructure for ecological environment protection. On the one hand, Guizhou needs to speed up its development and consolidate its achievements in poverty alleviation. On the other hand, it faces severe challenges from dwindling resources and degrading environment and unhealthy urbanization pattern. The Environmental Kuznets curve (EKC) theory shows that the environmental quality will deteriorate in the early stage of economic development, when the economic development exceeds a certain threshold level, the economic development will offset the environmental degradation, so as to improve the environmental quality. EKC illustrates the relationship between economic development and ecological environment. Therefore, in order to better measure the relationship between ecological environment and urbanization development in Guizhou Province, this paper puts forward the EKC inverted U-shaped hypothesis between ecological environment degradation and urbanization.

In recent years, more and more scholars have begun to study the coordination relationship between urbanization and ecological environment. Kirikkaleli and Kalmaz [1] found the moderating effect of urbanization brings changes to ecological environment in the short term and discovered the direct relationship between urbanization and ecological environment. Ramachandra et al. [2] used a spatial measurement model to analyze the impact of urbanization on ecological environment in India, concluding that overurbanization negatively affects ecological environment. Borck and Pflüger [3] explored the problems between urbanization and ecological environment in their respective countries, with the aid of core-periphery model, coupling model [4], and geographic information system (GIS) [5], respectively. Liu and Wang [6] demonstrated the good CCD between urbanization and ecological environment in Hang Zhou, China. Wang and He [7] confirmed that the CCD 
between urbanization and ecological environment of Shapingba District, Chongqing, reached the highly coordinated state in 2017. Cai et al. [8] analyzed the development trend of urbanization and ecological environment in Guiyang, based on the comprehensive index evaluation model.

Throughout the years, research on EKC focuses more on confirming its existence. Germani et al. [9] used the data of Italian provinces to confirm that there is an environmental Kuznets curve between environmental degradation and production. Iqbal et al. [10] confirmed the existence of U-shaped environmental Kuznets curve by using Pakistan data and found that at a certain level of economic growth, a $1 \%$ increase in per-capita income, can lead to reductions in environmental pollution by $2.88 \%$, $4.54 \%$, and $2.48 \%$. Through investigation, Arnaut and Javier [11] found that the KEC between economic growth and environment in Greenland is not an inverted $\mathrm{U}$-shaped, but a positive U-shaped. However, once the country began to expand its industry, the trend began to reverse. Zhang et al. [12] used the SO2 and GDP data of 30 provinces in China and found an inverted $\mathrm{N}$-shaped relationship between environmental pollution and economic growth. Yin et al. [13] adopted the spatial Dubin model, and the results showed that an evident "inverted U-shaped" EKC relationship existed between carbon intensity and electrification in China.

The previously mentioned studies have conducted qualitative and quantitative analyses on the relationship between urbanization and ecological environment. Most of them focus on the overall pattern in the selected areas, or on the trend of the time coupling model. Few have tackled the internal causes or improvement methods for the relationship. Besides, most scholars emphasize on developed cities and regions over backward regions like Guizhou and Yunnan. There is almost no attempt to test whether the relationship between urbanization and ecological environment follows the Kuznets curve, that is, whether it meets the inverted U-shaped hypothesis [14-20]. Hence, this paper decides to investigate the CCD between urbanization and ecological environment in Guizhou.

Exploring the CCD between urbanization and ecological environment in Guizhou helps to extract a development path different from traditional urbanization path, providing an important reference for the urbanization in backward areas. Studying the environmental Kuznets curve of Guizhou offers another explanation for how to realize the inflection point of the Kuznets curve and enter the descending segment of the inverted U-shaped curve.

Focusing on the entire province of Guizhou, this paper first introduces the research problem and reports the relevant studies. Then, the entropy weight method and coupling effect model were adopted to analyze the CCD between urbanization and ecological environment in Guizhou. Two prefectures with significantly different CCDs were compared to reveal the internal causes of the difference. Next, the authors tested whether the relationship between urbanization and ecological environment deterioration in Guizhou satisfies the inverted U-shaped hypothesis. Finally, several suggestions were presented for policy makers.

\section{Empirical Analysis}

This paper uses the entropy weight method to calculate the urbanization level and ecological environment level of Guizhou from 2013 to 2018 and analyzes the current status and trend of the urbanization level and ecological level of the province from 2013 to 2018 . Taking the CCD model of the province as the benchmark, the coupling effect between urbanization and ecological environment in Guizhou and its change trend were derived from the results of the stationarity test. No endogeneity test was conducted, because endogeneity is avoided by the entropy weight method. Then, the authors tested whether the relationship between urbanization and ecological environment deterioration in Guizhou satisfies the inverted U-shaped hypothesis and briefly explained the empirical results.

2.1. Model Selection. The coupling effect model mainly analyzes the level of coordinated development between things. In economics, four models are often adopted to analyze the relationship between two or more systems or subsystems, such as structural coupling model, hierarchical coupling model, spatial coupling model, and time coupling model:

$$
C_{n}=n \cdot\left(\frac{u_{1} u_{2} \ldots u_{n}}{\prod\left(u_{i}+u_{j}\right)}\right)^{1 / n},
$$

where $n$ is the number of subsystems; $u_{i}$ is the participation of the i-th subsystem; $C_{n}$ is the coupling degree of the $n$ subsystems. Before computing the CCD of a system, the weight and coordination index of each subsystem need to be calculated by

$$
\left\{\begin{array}{l}
T=\alpha_{1} u_{1}+\alpha_{2} u_{2}+\ldots+\alpha_{n} u_{n} \\
D=(C * T)^{1 / n}
\end{array}\right.
$$

where $n$ is the number of subsystems; $\alpha_{i}$ is the weight of the $i$ th subsystem; $u_{i}$ is the participation of the $i$-th subsystem; $T$ is the coordination index; $C$ is the coupling degree; and $D$ is the CCD. Here, the value of $n$ equals 2 , because this paper has two objects: the urbanization and ecological environment in Guizhou.

When it comes to weight determination, this paper assumes that urbanization and ecological environment are equally important for the sustainable development of Guizhou's economy. Hence, the weights of the two subsystems are by default equal: $\alpha_{1}=\alpha_{2}=0.5$. T stands for the comprehensive development level of urbanization and ecological environment. $D$ means the CCD between the two subsystems, namely, urbanization and ecological environment.

Based on the $D$ values, according to SPSS software for CCD classification, combined with our summary, the CCD was divided into four levels: uncoordinated, barely coordinated, coordinated, and well-coordinated (Table 1).

2.2. Data Selection. According to the key points of urban development [21-24], these paper hold that urbanization includes four primary indexes: population urbanization, 
TABLE 1: CCD levels.

\begin{tabular}{lc}
\hline $\mathrm{D}$ & Degree of coordination \\
\hline $\mathrm{D} \leqq 0.4$ & Uncoordinated \\
$0.4<\mathrm{D} \leqq 0.6$ & Barely coordinated \\
$0.6<\mathrm{D} \leqq 0.8$ & Slightly coordinated \\
$0.8<\mathrm{D}$ & Strongly coordinated \\
\hline
\end{tabular}

economic urbanization, spatial urbanization, and social urbanization. Among the secondary indexes, the negative index is the population density (person $/ \mathrm{km}^{2}$ ), and the positive indexes include number of new urban employees (10,000 people), percapita gross domestic product (GDP) (10,000 yuan), secondary industry output (100 million yuan), secondary industry output (100 million yuan), tertiary industry output (100 million yuan), social retail sales (100 million yuan), actual year-end road length $(\mathrm{km})$, per-capita living area $\left(\mathrm{m}^{2}\right)$, built-up area $\left(\mathrm{km}^{2}\right)$, number of ordinary middle schools (each), number of licensed physicians per thousand people (each/1,000), and per-capita disposable income of urban residents (yuan). The relevant data were selected from the official website of Guizhou Provincial Bureau of Statistics.

Drawing on the pressure-state-response model proposed by the Canadian statistician Rapport [25], this paper constructs a three-dimensional index system for ecological environment. The primary indexes include environmental pressure, environmental state, and response measure. Among the secondary indexes, the negative indexes include air quality index (AQI), industrial sulfur dioxide emissions (ton), industrial soot emissions (ton), industrial wastewater discharge (ton), and total domestic sewage discharge (ton). The positive indexes include green area in built-up area $\left(\mathrm{km}^{2}\right)$, forest coverage (\%), per-capita water resources $\left(\mathrm{m}^{3}\right)$, industrial pollution control expenses (100 million yuan), domestic garbage clean-up volume (10,000 ton), daily treatment of municipal sewage $\left(10,000 \mathrm{~m}^{3}\right)$, and area of soil erosion treated in the current year $\left(\mathrm{km}^{2}\right)$. The relevant data were downloaded from the National Bureau of Statistics, China.

By entropy weight method, the weight of each index for urbanization and ecological environment was calculated for Guizhou in 2018 (Table 2).

2.3. Analysis on Results of the Entropy Weight Method. Figure 1 presents the final scores of urbanization in Guizhou in 2018, as obtained by the entropy weight method. The prefectures in red are medium-to-high urbanization areas, with a score greater than 0.5 ; those in light red are mediumto-low urbanization areas, with a score between 0.2 and 0.5 ; those in yellow are low urbanization areas, with a score smaller than 0.2 . It can be seen that the urbanization level varied greatly within Guizhou. The northern prefectures were more urbanized than the southern ones. The clear disparity comes from the large differences in culture, economy, and living customs, due to the large number of ethnic monitories in Guizhou.

Figure 2 presents the final scores of ecological environment in Guizhou in 2018, as obtained by the entropy weight method. The prefectures in dark green have a good ecological environment, with a score greater than 0.5 ; those in light green have a general ecological environment, with a score between 0.2 and 0.5 ; those in yellow have a poor ecological environment, with a score smaller than 0.2 . It can be seen that the variation of ecological environment in Guizhou is not consistent with that of urbanization.

Urbanization is accompanied by industrialization, which will worsen the ecological environment. Generally speaking, urbanization and ecological environment development in Guizhou Province are in line with EKC theory, that is, low urbanization and good ecological environment in the early stage of urbanization, such as southeast and southwest Guizhou. Before the midterm urbanization reaches the critical point, the urbanization is medium and the ecological environment is poor, such as Liupanshui. After exceeding the critical point, the degree of urbanization is high and the ecological environment is gradually getting better, such as other cities in Guizhou (except Anshun).

Then, we briefly analyze the differences between urbanization and ecological environment in the province. According to the urban development theory, Guiyang is the provincial capital city with rapid urbanization development. Combined with EKC theory, urbanization and ecological environment development are in Section C in Figure 3. Zunyi is located between Guiyang and Chongqing, radiated by two provincial capitals, with developed transportation and rapid urbanization. Combined with EKC theory, urbanization and ecological environment development are in Section C in Figure 3. Southeast and southwest Guizhou are ethnic autonomous regions and are far away from the provincial capital, with slow urbanization development. Combined with EKC theory, urbanization and ecological environment development are in Section A in Figure 3. Liupanshui has convenient transportation. Although it is between the two provincial capitals of Guiyang and Kunming, it is far away from both provincial capitals, so the urbanization development is only faster than that of southeast and southwest Guizhou. Combined with EKC theory, the urbanization and ecological environment development are in Section B in Figure 3. Other cities (except Anshun) are close to the provincial capital, and urbanization develops rapidly. Combined with EKC theory, urbanization and ecological environment development are in Section D in Figure 3.

Anshun is special, so we cannot explain the double low situation of low urbanization and poor ecological environment by EKC theory alone. Here is a brief discussion of the possible reasons: (1) because the data used is the overall data of the city, it has a great relationship with the area of urban jurisdiction. Anshun has a small jurisdiction and is 
TABle 2: Index weights of urbanization and ecological environment.

\begin{tabular}{|c|c|c|c|}
\hline Index & Primary index & Secondary index & \\
\hline \multirow{12}{*}{ Urbanization } & \multirow{2}{*}{ Population urbanization 0.11} & Number of new urban employees (10,000 people) & 0.08 \\
\hline & & Population density $\left(\right.$ person $\left./ \mathrm{km}^{2}\right)$ & 0.03 \\
\hline & \multirow{4}{*}{ Economic urbanization 0.44} & Per-capita gross domestic product (GDP) $(10,000$ yuan $)$ & 0.09 \\
\hline & & Secondary industry output (100 million yuan) & 0.09 \\
\hline & & Tertiary industry output (100 million yuan) & 0.12 \\
\hline & & Social retail sales (100 million yuan) & 0.14 \\
\hline & \multirow{3}{*}{ Spatial urbanization 0.22} & Actual year-end road length $(\mathrm{km})$ & 0.06 \\
\hline & & Per-capita living area $\left(\mathrm{m}^{2}\right)$ & 0.06 \\
\hline & & Built-up area $\left(\mathrm{km}^{2}\right)$ & 0.10 \\
\hline & \multirow{3}{*}{ Social urbanization 0.23} & Number of ordinary middle schools (each) & 0.07 \\
\hline & & Number of licensed physicians per thousand people (each/1,000) & 0.06 \\
\hline & & Per-capita disposable income of urban residents (yuan) & 0.10 \\
\hline \multirow{12}{*}{ Ecological environment } & \multirow{4}{*}{ Environmental pressure 0.13} & Industrial sulfur dioxide emissions (ton) & 0.04 \\
\hline & & Industrial soot emissions (ton) & 0.03 \\
\hline & & Industrial wastewater discharge (ton) & 0.04 \\
\hline & & Total domestic sewage discharge (ton) & 0.02 \\
\hline & \multirow{4}{*}{ Environmental state 0.33} & Green area in built-up area $\left(\mathrm{km}^{2}\right)$ & 0.14 \\
\hline & & Forest coverage $(\%)$ & 0.05 \\
\hline & & Air quality index (AQI) & 0.03 \\
\hline & & Per-capita water resources $\left(\mathrm{m}^{3}\right)$ & 0.11 \\
\hline & \multirow{4}{*}{ Response measure 0.54} & Industrial pollution control expenses (100 million yuan) & 0.10 \\
\hline & & Domestic garbage clean-up volume (10,000 ton) & 0.11 \\
\hline & & Daily treatment of municipal sewage $\left(10,000 \mathrm{~m}^{3}\right)$ & 0.20 \\
\hline & & Area of soil erosion treated in the current year $\left(\mathrm{km}^{2}\right)$ & 0.13 \\
\hline
\end{tabular}

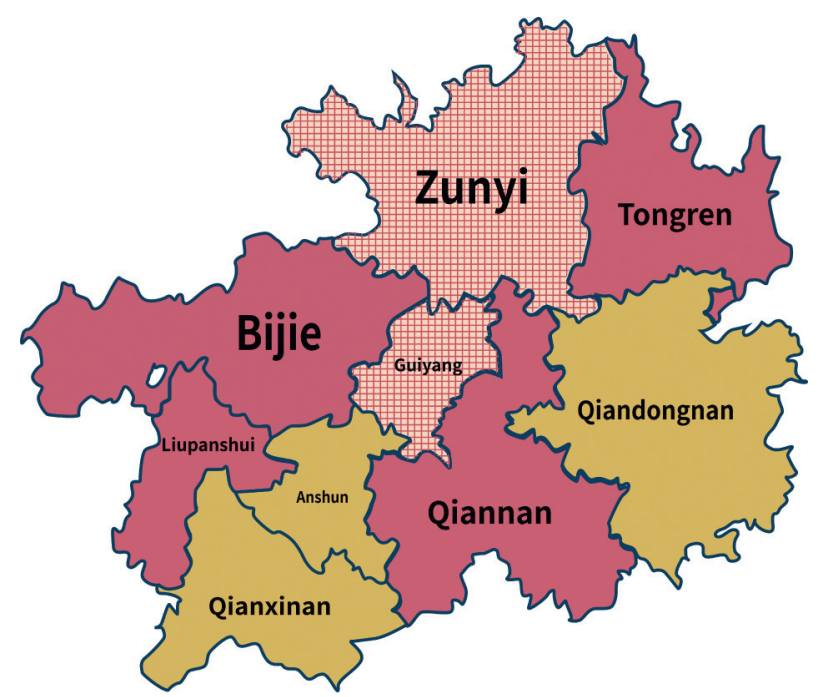

FiguRE 1: Urbanization scores of different prefectures in Guizhou, 2018.

not the provincial capital city, so its data is smaller than other cities as a whole, and there is a large gap in horizontal comparison with other cities. Therefore, combined with the longitudinal analysis results of each city, the comparative study is more accurate. (2) Anshun City Center is close to Guiyang. Due to the siphon effect of the provincial capital and the absence of natural barriers, such as mountains and rivers between the two places, the transportation is convenient, which accelerates the population flow, so the urbanization development is slower. (3) Anshun is one of the world's karst landform concentration areas, with rich rainfall, unstable landform, and serious water and soil loss, which also seriously hinders the urbanization development of Anshun and highlights the ecological environment problems of Anshun.

\subsection{Analysis Procedure}

2.4.1. Benchmark Model. The CCD values between urbanization and ecological environment in Guizhou during 2013-2018 were calculated by SPSS. The results in Table 3 show a high coupling between urbanization and ecological environment in Guizhou, which surpassed 0.9 as early as 


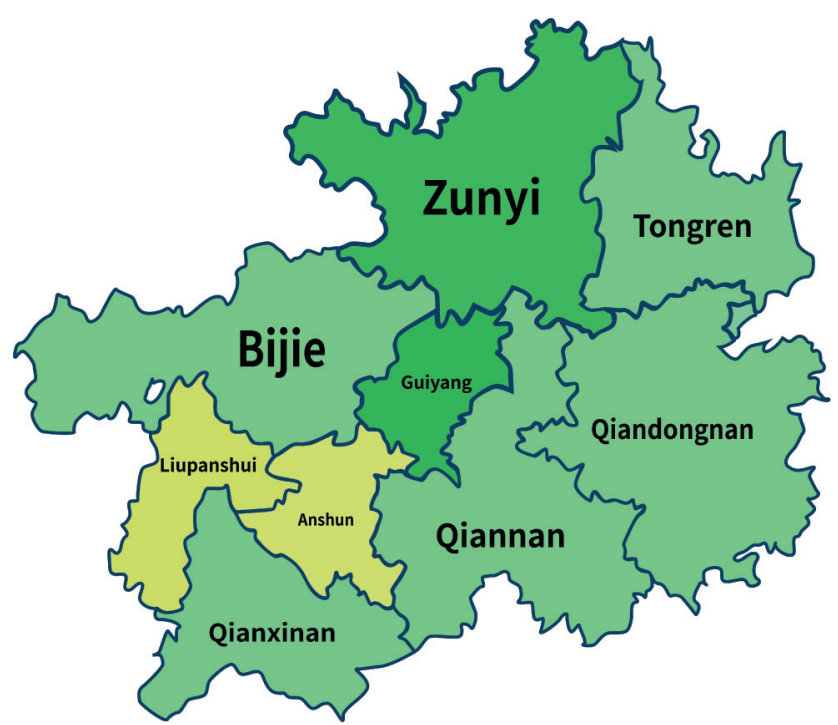

Figure 2: Ecological environment scores of different prefectures in Guizhou, 2018.

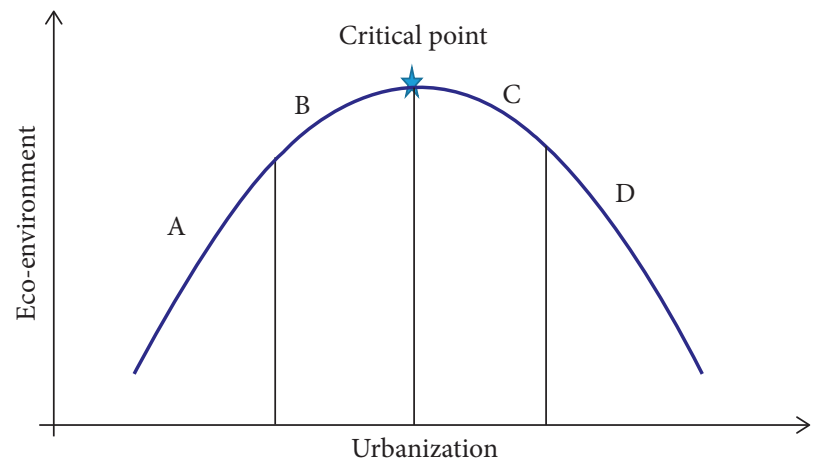

Figure 3: The environmental Kuznets curve (EKC).

2013. The coordination index $T$ exhibited an upward trend, indicating that the comprehensive development level of urbanization and ecological environment in Guizhou improved significantly from 2013 to 2018. In addition, the CCD also showed an upward trend, a sign of the constant deepening of the CCD between urbanization and ecological environment subsystems in Guizhou. Referring to Table 1, the CCD of Guizhou increased from barely coordinated to well-coordinated during 2013-2018. Hence, there was a growing coordination between the development of urbanization and that of ecological environment in Guizhou.

From the previously mentioned results on urbanization, ecological environment, and their CCD of Guizhou in 2013-2018, it can be inferred that the urbanization process and ecological environment state of Guizhou had been developed in a coordinated manner. The ecological environment was not neglected in the course of urbanization. In particular, during 2017-2018, both the urbanization process and ecological environment state of Guizhou were greatly improved, precisely when the CCD between urbanization and ecological environment in Guizhou reached the slightly coordinated level. Hence, both the urbanization and ecological environment in Guizhou improve with the increase in the CCD.

2.4.2. Analysis on the Coordination Relationship in Each Prefecture. This section carries out spatial and temporal analyses on the coordination relationship between urbanization and ecological environment in various prefectures of Guizhou. First, the coordination relationships in 2013 and 2018 between different prefectures were investigated horizontally. Then, the coordination relationships in every prefecture through 2013-2018 were investigated longitudinally. Finally, the coordination relationships were summarized for each prefecture.

(1) Spatial Analysis. Figure 4 shows the coordination relationships between urbanization and ecological environment in each prefecture in 2013 and 2018. Whether it is 2013 or 2018, Guiyang was strongly coordinated, Zunyi was slightly coordinated, and Anshun was uncoordinated; all the other prefectures were barely coordinated. 
TABle 3: CCD values.

\begin{tabular}{lcccc}
\hline Year & Coupling degree $(\mathrm{C})$ & Coordination index (D) & CCD (D) & CCD level \\
\hline 2013 & 0.92 & 0.241 & 0.471 & Barely coordinated \\
2014 & 0.945 & 0.175 & 0.407 & Barely coordinated \\
2015 & 0.954 & 0.231 & 0.469 & Barely coordinated \\
2016 & 0.991 & 0.324 & 0.567 & Barely coordinated \\
2017 & 0.958 & 0.439 & 0.648 & Slightly coordinated \\
2018 & 0.997 & 0.884 & 0.939 & Strongly coordinated \\
\hline
\end{tabular}

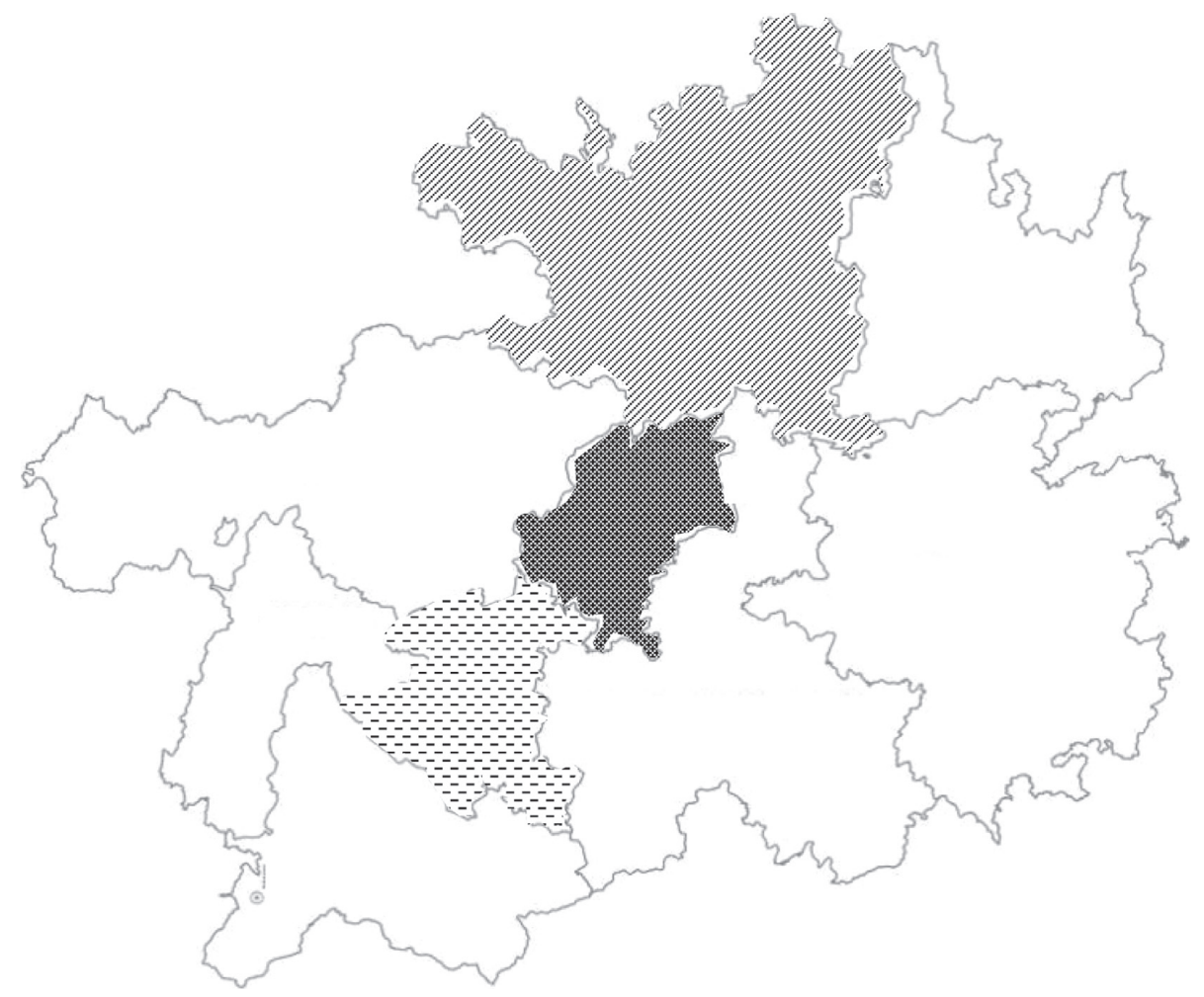

Strongly coordinated prefecture $(\mathrm{D} \geq 0.8)$

$\mathbb{Z}$ Slightly coordinated prefecture $(0.6<\mathrm{D} \leq 0.8)$

$\square$ Barely coordinated prefecture $(0.4<\mathrm{D} \leq 0.6)$

-- Uncoordinated prefecture $(\mathrm{D} \leq 0.4)$

FIGURE 4: Coordination relationships between urbanization and ecological environment in each prefecture in 2013 and 2018.

The spatial analysis shows that the coordination relationships between urbanization and ecological environment in 2013 and 2018 varied greatly from prefecture to prefecture. The higher the urbanization level, the better the ecological environment state.

Guiyang and Zunyi won the title of National Forest City successively. During economic development, the two cities have stressed ecological civilization and attached equal importance to development and ecology. In contrast, the coupling and coordination effect between urbanization and ecological environment was not very good in other prefectures, especially in Anshun. This is probably related to the construction of Guiyang-Anshun New District, which inevitably hinders the urbanization and ecological environment protection in Anshun.
Spatial analysis mainly aims to reveal the prefectural differences in Guizhou. However, Guizhou is a province with numerous ethnic groups, multiple autonomous prefectures, and complex terrain. As a result, the prefectures vary greatly in conditions and development levels. Spatial analysis alone cannot fully reveal the coordination degree between urbanization and ecological environment in every prefecture. It can roughly compare the coordinated development levels between different prefectures at a certain time point. The specific condition of each prefecture needs to be understood through temporal analysis.

(2) Temporal Analysis. As shown in Table 4, the coordination index of urbanization and ecological environment in every prefecture increased from 2013 to 2018, indicating a 
TABLE 4: Coordination indices of each prefecture in Guizhou during 2013-2018.

\begin{tabular}{lccccccccc}
\hline Coordination index $(\mathrm{T})$ & Guiyang & Liupanshui & Zunyi & Anshun & Bijie & Tongren & Qianxinan & Qiandongnan & Qiannan \\
\hline 2013 & 0.235 & 0.218 & 0.204 & 0.121 & 0.191 & 0.259 & 0.143 & 0.224 \\
2014 & 0.299 & 0.331 & 0.236 & 0.29 & 0.252 & 0.256 & 0.317 & 0.27 \\
2015 & 0.382 & 0.5 & 0.416 & 0.497 & 0.424 & 0.326 & 0.491 & 0.21 \\
2016 & 0.579 & 0.547 & 0.585 & 0.629 & 0.633 & 0.55 & 0.518 & 0.52 \\
2017 & 0.744 & 0.642 & 0.752 & 0.774 & 0.689 & 0.666 & 0.583 & 0.584 \\
2018 & 0.849 & 0.732 & 0.732 & 0.791 & 0.767 & 0.765 & 0.71 & 0.37 \\
\hline
\end{tabular}

significant and continuous improvement to the comprehensive development level of urbanization and ecological environment in every prefecture. The temporal analysis agrees with the overall analysis on Guizhou's CCD. This means the analysis results are reliable, and every prefecture works hard to promote urbanization and ecological civilization. Although spatial analysis indicates that some prefectures lagged slightly, temporal analysis found that these prefectures are struggling to develop and protect ecological environment, and their backward positions resulted from their conditions rather than the lack of efforts.

As shown in Table 5 (B means barely coordinated, L means slightly coordinated, and S means strongly coordinated), from 2013 to 2018, the coordination between urbanization and ecological environment of every prefecture changed from barely coordinated to strongly coordinated; that is, every prefecture in Guizhou is devoted to the parallel development of ecological civilization and urbanization.

Through the sample period, the prefectures with relatively good CCD levels are Guiyang, Zunyi, Anshun, Bijie, Tongren, and Qiannan; the prefectures with relatively poor CCD levels are Liupanshui, Qianxinan, and Qiandongnan. Since the former prefectures differ slightly in the variation of CCD, Guiyang was chosen as an example to explore the causes of the variation. Meanwhile, Liupanshui was selected to analyze the reasons for slow CCD growth, because the prefecture performed poorly in urbanization and ecological environment and ranked the last among the prefectures with relatively poor CCD levels.

(3) Further Analysis on Guiyang and Liupanshui. The scores (Figure 5) of Guiyang and Liupanshui, which were obtained by entropy weight method, suggest that the two prefectures did not overlook the construction of ecological construction in the course of urbanization, that is, not pursuing urbanization at the cost of ecological environment. Before 2015, Liupanshui also stuck to the strategy of attaching equal importance to ecological civilization and urbanization. However, the ecological environment level of the prefecture suddenly dropped in 2016, accompanied by a surge of the urbanization curve. In 2017, the ecological environment rebounded significantly, while the urbanization dropped slightly. Therefore, Liupanshui promoted urbanization at the expense of ecological environment for a short period of time. As a result, the CCD of Liupanshui, which was higher than that of Guiyang ( 0.7 vs. 0.6 ) before 2015, dropped out of the rank of the prefectures with relatively good urbanization and ecological environment levels, as the ecological environment deteriorates in the course of urban development.
In either city, the economic indices that directly impact urbanization did not change abruptly in 2013-2018, but evenly rose in that period. The only exception is the slight decline in secondary industry output of Liupanshui in 2017. The analysis on the major impactors of ecological environment shows that Guiyang enhanced its treatment measures in response to the heavy environmental pressure. For comparison, the environmental pressure of Liupanshui was taken into account.

Table 6 presents the environmental pressure scores of Liupanshui in 2013-2018 as obtained by entropy weight method. Since environmental pressure is a negative index, the smaller the score, the greater the environmental pressure. That is, a large score is relatively favorable. As can be seen from Table 6, the environmental pressure of Liupanshui clearly increased in 2016, which is directly driven by the marked growth in industrial wastewater discharge, industrial sulfur dioxide emissions, and industrial soot emissions. The obvious increase indicates that many factory operations took place in 2016-2017, but little consideration was paid to environmental protection. Urbanization is accompanied by industrialization. Many industrialization operations will inevitably lead to the development of urbanization. Perhaps, Liupanshui thought that the environmental pressure is not an important impactor of its ecological environment. As a result, the prefecture stepped up the industrial development while ignoring the environmental carrying capacity in 2016, which eventually boosted the urbanization and suppressed the ecological environment. That is why the CCD in Liupanshui plunged from 0.7 to 0.5 .

2.4.3. Test on Inverted U-Shaped Hypothesis. During literature review, this paper mentions the inverted $\mathrm{U}$-shaped hypothesis for the relationship between the urbanization and ecological environment. Hence, this subsection attempts to test the hypothesis based on the urbanization and ecological environment scores obtained by entropy weight method for Guizhou in 2013-2018. Since the relationship between the urbanization and ecoenvironmental degradation is assumed to be discussed, the score of ecoenvironmental degradation is replaced by one minus ecoenvironmental score. The ecological environment deterioration was represented by the difference between one and the ecological environment curve. Then, the relationship between the ecological environment deterioration score and the urbanization score was compiled into a line chart (Figure 6). It can be seen that the relationship between the ecological environment deterioration and urbanization is indeed shaped as an inverted 
TABLE 5: CCD values and levels of each prefecture in Guizhou.

\begin{tabular}{lccccccccc}
\hline CCD (D) value & Guiyang & Liupanshui & Zunyi & Anshun & Bijie & Tongren & Qianxinan & Qiandongnan & Qiannan \\
\hline 2013 & 0.479 & 0.459 & 0.425 & 0.347 & 0.436 & 0.508 & 0.375 & 0.444 \\
2014 & 0.546 & 0.575 & 0.483 & 0.539 & 0.501 & 0.497 & 0.561 & 0.453 \\
2015 & 0.617 & 0.707 & 0.644 & 0.705 & 0.65 & 0.57 & 0.697 & 0.609 \\
2016 & 0.759 & 0.739 & 0.764 & 0.793 & 0.79 & 0.742 & 0.707 & 0.72 \\
2017 & 0.861 & 0.785 & 0.864 & 0.878 & 0.83 & 0.814 & 0.75 & 0.763 \\
2018 & 0.921 & 0.851 & 0.856 & 0.889 & 0.874 & 0.872 & 0.841 & 0.903 \\
\hline CCD level & & & & & & & & 0.735 \\
2013 & B & B & B & B & B & B & B & B \\
2014 & B & B & B & B & B & B & B & B \\
2015 & L & L & L & L & L & B & L & B \\
2016 & L & L & L & L & L & L & L & B \\
2017 & S & L & S & S & S & S & L & L & L \\
2018 & S & S & S & S & S & S & S & L & S \\
\hline
\end{tabular}
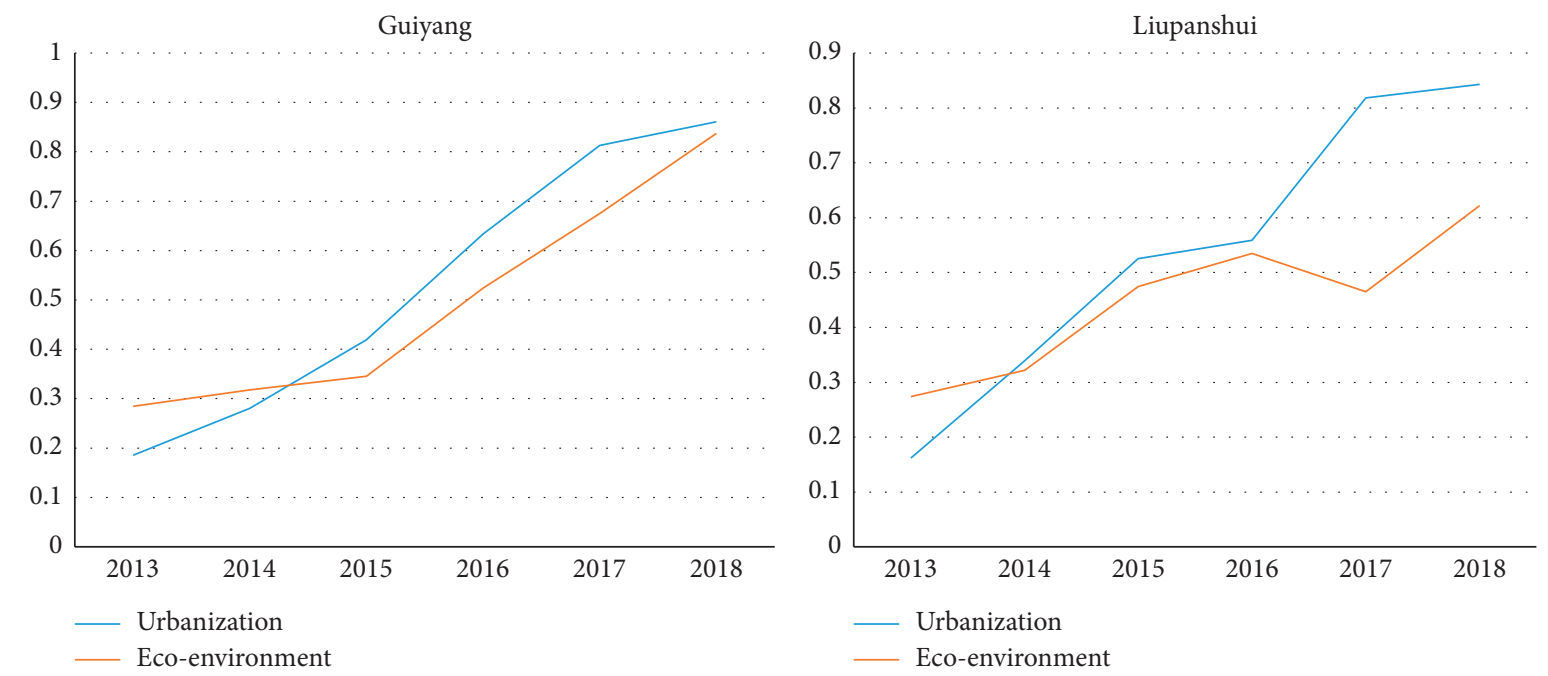

FIGURE 5: Urbanization and ecological environment levels of Guiyang and Liupanshui in 2013-2018.

TABLE 6: Environmental pressure scores of Liupanshui in 2013-2018.

\begin{tabular}{cccccc}
\hline Year & $\begin{array}{c}\text { Air quality index } \\
(\text { AQI })\end{array}$ & $\begin{array}{c}\text { Industrial sulfur dioxide } \\
\text { emissions }\end{array}$ & $\begin{array}{c}\text { Industrial soot } \\
\text { emissions }\end{array}$ & $\begin{array}{c}\text { Industrial wastewater } \\
\text { discharge }\end{array}$ & $\begin{array}{c}\text { Total domestic sewage } \\
\text { discharge }\end{array}$ \\
\hline 2013 & 0.000 & 0.000 & 0.033 & 0.062 & 0.032 \\
2014 & 0.036 & 0.015 & 0.000 & 0.049 & 0.026 \\
2015 & 0.036 & 0.027 & 0.027 & 0.061 & 0.022 \\
2016 & 0.035 & 0.061 & 0.038 & 0.065 & 0.046 \\
2017 & 0.036 & 0.031 & 0.033 & 0.000 & 0.050 \\
2018 & 0.040 & 0.043 & 0.042 & 0.010 & 0.000 \\
\hline
\end{tabular}

U-shaped curve. The right segment of the curve starts from 2013; that is, the ecological environment deteriorated with the growing level of urbanization since 2013.

Located on the Tropic of Cancer, Guizhou boasts a pleasant climate, diverse ethnic groups, and rich resources. China requires the province to stick to two bottom lines: development and ecology. Hence, the urbanization of Guizhou must not violate the bottom line of ecology. From this perspective, economic development of Guizhou in recent years has followed a sustainable development path, which is different from that in the developed coastal areas. In the light of the urbanization development in Guizhou, the fact that the relationship between urbanization and ecological environment deterioration follows the right segment of inverted U-shaped curve is of great reference significance for other places. 


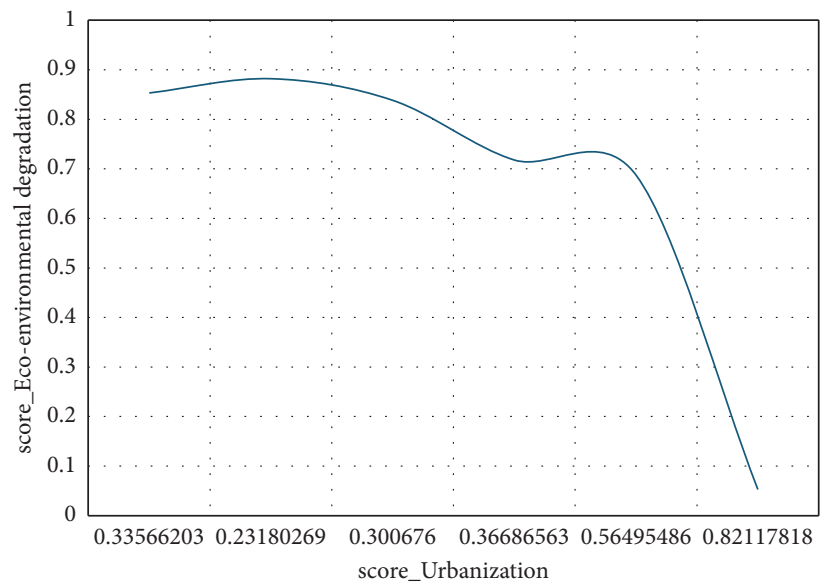

FIGURE 6: Curve between urbanization and ecological environment deterioration of Guizhou in 2013-2018.

\section{Conclusions}

(1) The CCD between urbanization and ecological environment in Guizhou continued to improve from 2013 to 2018. The higher the CCD level, the faster the development of urbanization and ecological environment. In addition, the relationship between the urbanization of Guizhou and the deterioration of ecological environment presented an inverted U-shape, that is, the left segment of the environmental Kuznets curve, reaching the extreme situation that urbanization and ecological environment develop basically in the same direction.

(2) Guizhou has a different path to urbanization from the traditional model. Most places choose the urbanization path of industrialization-urbanization-ecological environment protection, which pursues industrialization before protecting environment. By contrast, Guizhou chooses to implement industrialization and urbanization within the carrying capacity of ecological environment, which promotes the urbanization and ecological environment simultaneously. Combined with Conclusion (1), it can be seen that the urbanization path of Guizhou accelerates the speed of urbanization, and the economic growth. For simplicity, this path is referred to as balance-upgrading path.

(3) Comparing a prefecture with good CCD and a prefecture with poor CCD, it is learned that the prefectures with good CCD never neglected the environmental governance in the course of urbanization and industrialization, while those with poor CCD overlooked the governance of ecological environment while vigorously pursuing industrial growth, due to their traditionally small environmental pressure; as a result, the latter prefectures witnessed a jump in urbanization and a drop in the ecological environment level.

\section{Data Availability}

The data used to support the findings of this study are available from the corresponding author upon request. The data source is the Urban Statistical Yearbook of Guizhou Province and the statistical data of relevant urban environmental protection bureau. The data are true and reliable.

\section{Conflicts of Interest}

The authors declare that they have no conflicts of interest.

\section{Acknowledgments}

This work was supported by the "Upgrading of Industrial Structure in Guizhou Province under New Structural Economics," a school-level project of Guizhou University of Finance and Economics (grant no. 2019XYB14).

\section{References}

[1] D. Kirikkaleli and D. B. Kalmaz, "Testing the moderating role of urbanization on the environmental Kuznets curve: empirical evidence from an emerging market," Environmental Science and Pollution Research, vol. 27, no. 30, pp. 3816938180, 2020.

[2] T. V. Ramachandra, J. Sellers, H. A. Bharath, and B. Setturu, "Micro level analyses of environmentally disastrous urbanization in Bangalore," Environmental Monitoring and Assessment, vol. 191, no. 3, pp. 1-13, 2019.

[3] R. Borck and M. Pflüger, "Green cities? Urbanization, trade, and the environment," Journal of Regional Science, vol. 59, no. 4, pp. 743-766, 2019.

[4] J. Zheng, Y. Hu, T. Boldanov et al., "Comprehensive assessment of the coupling coordination degree between urbanization and ecological environment in the Siberian and Far East Federal Districts, Russia from 2005 to 2017," PeerJ, vol. 8, Article ID e9125, 2020.

[5] S. U. Khan, D. Raza, U. Saeed et al., "Evaluation of foliage spread conversion into industrial land under the significance of urbanization and environment," Fresenius Environmental Bulletin, vol. 29, no. 6, pp. 4612-4623, 2020.

[6] Q. J. Liu and L. H. Wang, "Examination of a coupling coordination relationship between urbanization and the ecoenvironment: case study of Hangzhou," Environmental Sciences, vol. 38, no. 10, pp. 4214-4222, 2018.

[7] L. P. Wang and T. R. He, "Study on the coordinated relationship between urbanization level and ecological 
environment in Shapingba District from 1998 to 2017," Journal of Chongqing Normal University (Natural Science Edition), vol. 37, no. 3, pp. 129-146, 2020.

[8] Z. R. Cai, Y. H. Li, and X. D. Li, "Study on the coupling of urbanization and ecological environment in Guiyang City," Ecological Science, vol. 36, no. 5, pp. 96-203, 2017.

[9] A. R. Germani, A. P. Ker, and A. Castaldo, "On the existence and shape of an environmental crime Kuznets Curve: a case study of Italian provinces," Ecological Indicators, vol. 108, p. $105685,2020$.

[10] N. Iqbal, A. Khan, A. S. Gill, and Q. Abbas, "Nexus between sustainable entrepreneurship and environmental pollution: evidence from developing economy," Environmental Science and Pollution Research, vol. 27, no. 29, pp. 36242-36253, 2020.

[11] J. Arnaut and J. Lidman, "Environmental sustainability and economic growth in Greenland: testing the environmental Kuznets curve," Sustainability, vol. 13, no. 3, p. 1228, 2021.

[12] Z. L. Zhang, R. M. Ren, and X. M. Zhu, "Reexamination of environmental Kuznets curve in China," Contemporary economic science, vol. 124, no. 5, pp. 23-30, 2012.

[13] Z. H. Yin, J. H. Cheng, W. H. Chen, and X. Lu, "Environmental Kuznets inverted U-shaped relation between carbon intensity and electrification in China's low-carbon transformation process and its policy implications," Environmental conformity Assessment, vol. 13, no. 3, pp. 40-47, 2021.

[14] A. Rehman, H. Ma, M. Z. Chishti, I. Ozturk, M. Irfan, and M. Ahmad, "Asymmetric investigation to track the effect of urbanization, energy utilization, fossil fuel energy and CO2 emission on economic efficiency in China: another outlook," Environmental Science and Pollution Research, vol. 28, no. 14, pp. 17319-17330, 2021.

[15] Z. Gong, Q. Kong, and J. Tan, “Analysis on multidimensional poverty reduction of industrial structure upgrading based on provincial panel data and spatial Durbin model," International Journal of Sustainable Development and Planning, vol. 15, no. 8, pp. 1197-1204, 2020.

[16] K.-A. Nguyen and Y.-A. Liou, "Mapping global eco-environment vulnerability due to human and nature disturbances," Methods (Duluth), vol. 6, pp. 862-875, 2019.

[17] H. Hu, L. Dong, H. Zhang, H. Tang, and D. Yin, "Panel data analysis on the influence of environmental regulations on the inflow of foreign direct investment in China," International Journal of Sustainable Development and Planning, vol. 15, no. 7, pp. 1035-1044, 2020.

[18] A. K. Nguyen, Y.-A. Liou, M.-H. Li, and T. A. Tran, "Zoning eco-environmental vulnerability for environmental management and protection," Ecological Indicators, vol. 69, pp. 100-117, 2016.

[19] B. S. Cao, C. X. Zou, J. X. Gao, and P. He, "Ecological security evaluation method and its application," Journal of Ecology and Rural Environment, vol. 35, no. 8, pp. 53-963, 2019.

[20] D. Liang, Q. Fu, Y. Xu, X. Shao, and Y. Qi, "Modelling and dynamic analysis of water resource-ecology-economy system in water conservation areas," International Journal of Design \& Nature and Ecodynamics, vol. 15, no. 3, pp. 315-323, 2020.

[21] N. Okamoto, "Extended input-output model for urbanization: an empirical test using Chinese data," Journal of Economic Structures, vol. 10, no. 1, pp. 1-24, 2021.

[22] M. Ariken, F. Zhang, N. w. Chan, and H.-t. Kung, "Corrigendum to "Coupling coordination analysis and spatiotemporal heterogeneity between urbanization and eco-environment along the silk road economic belt in China" [Ecol. Indic. (2021) 107014]," Ecological Indicators, vol. 121, Article ID 107191, 2021.
[23] Y. Zhang, Q. Y. Yang, C. Li, and M. Y. Yang, "Evaluation and comparative analysis on the development quality of new urbanization in Chongqing," Economic Geography, vol. 35, no. 7, pp. 79-86, 2015.

[24] J. Senosiain, "Urban regreeneration: green urban infrastructure as a response to climate change mitigation and adaptation," International Journal of Design \& Nature and Ecodynamics, vol. 15, no. 1, pp. 33-38, 2020.

[25] D. Rapport, R. Costanza, and A. J. McMichael, "Assessing ecosystem health," Trends in Ecology \& Evolution, vol. 13, no. 10, pp. 397-402, 1998. 